\title{
Revisiting the Dusunic Boat Lutes of Sabah: Disappearing Musical Traditions
}

\author{
Jacqueline Pugh-Kitingan \\ Faculty of Social Sciences and Humanities \\ and \\ Borneo Institute for Indigenous Studies \\ Universiti Malaysia Sabah \\ e-mail: jacquie@ums.edu.my \\ *Corresponding author: jacquie@ums.edu.my
}

Published: 9 December 2020

Cite this article (APA): Pugh-Kitingan, J. (2020). Revisiting the Dusunic boat lutes of Sabah: Disappearing musical traditions, 9, 115-137.https://doi.org/10.37134/mjm.vol9.9.2020

\begin{abstract}
The Kadazan Dusun sundatang from Tambunan, the Rungus sundatang, and the Lotud gagayan are three kinds of boat lutes from Sabah. Each is carved from a single log of jackfruit wood, but they vary structurally. Resembling somewhat Philippine boat lutes, they differ from the sape-types of Sarawak and Kalimantan. They are played solo in non-ritual contexts. The gagayan, however, was played in pairs and the Tambunan sundatang was sometimes accompanied by a hand-held gong when accompanying the slow, sedate magarang sundatang dance. Today, there are very few musicians playing the unique Tambunan sundatang, while the Lotud gagayan has recently declined with the demise of older performers. The Rungus sundatang is still extant and continues to be performed in many longhouses. This paper discusses these three types of Dusunic boat lutes, their structures, performance practices and music, and suggests a possible origin for these kinds of instruments found in northern Borneo.
\end{abstract}

Keywords: boat lutes, gagayan, Kadazan Dusun, Lotud, Rungus, Sabah, sundatang

\section{Introduction}

Boat lutes, so named by western scholars because their long slender soundboxes somewhat resemble boat shapes, were once widely played throughout Borneo, the Philippines, and Central and Southern Sulawesi. Those generally known as kucapi in the southern Philippines are normally double-stringed and have small bodies and long necks (Brandeis, 2012, 2017, 2019). These differ from the various kinds of sape or sampe found in Sarawak and Kalimantan that have short necks, long rectangular bodies, and differing numbers of strings according to culture and location (Matusky, 1986, pp.188-189; Matusky \& Tan, 2017, pp. 286-287). Boat lutes are also played among the cultures of Central and South Sulawesi and have narrow bodies like the Philippine types, but with short necks (Daud, 2011). Sabah also has so-called boat lutes which, like those of the surrounding regions, are each carved from single logs of certain kinds of jackfruit tree wood. Jackfruit woods are preferred, because they are soft and can be easily carved into the required shape, and are also resistant to termites. The instruments have two strings, with frets placed below the higher pitched string on the right side of the neck from the observer's viewpoint ${ }^{1}$.

Three main types of long-necked boat lutes are found among the indigenous Dusunic peoples of Sabah. ${ }^{2}$ These include the sundatang of the Kadazan Dusun of Tambunan District, the sundatang of 
the Rungus of Kudat District, and the large gagayan of the Lotud of Tuaran District (Figure 1). Except for the Lotud gagayan which was normally played in pairs, these are usually solo instruments. They are performed in non-ritual contexts for entertainment and personal expression. These three boat lute genres were chosen for discussion here because they represent three distinct types of such instruments from three musical traditions that, until recently, were still being performed.

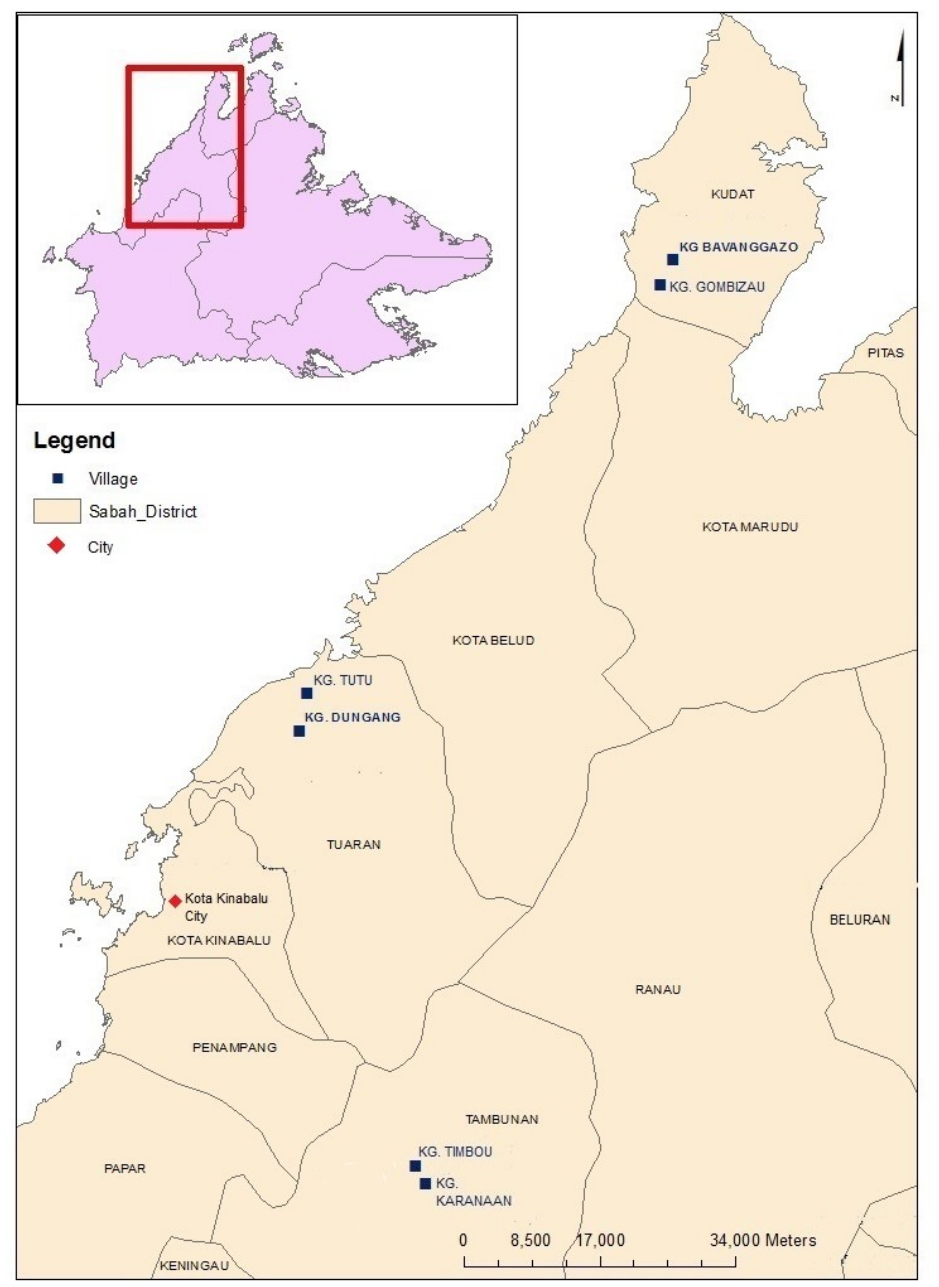

Figure 1. Map showing locations of villages mentioned in this article. (Source: Oliver Valentine Eboy, 12 November 2020)

The ancient indigenous Dusunic Family of Languages consists of around ten major languages $\left(\right.$ Ethnologue $\left.^{\circledR}, 2016\right)$. Dusunic ethnic groups traditionally inhabit parts of the central interior, western and northern Districts of Sabah. They are non-segmented, acephalous societies with bilateral kinship systems and gender balance. As large sedentary agrarian societies, they cultivate wet rice on alluvial plains and dry rice in mountainous areas. Traditionally, they lived in villages composed of longhouses in which each conjugal family occupied a private apartment. The last Borneo smallpox pandemic of 1904-1905 and World War II led to the demise of Dusunic longhouses, except among the Rungus where many contemporary longhouses are found.

Of the three Dusunic cultures whose lutes are the focus of this discussion, the Kadazan Dusun or Dusun are the largest single ethnic group in Sabah with a population of approximately $25 \%$ of the state's population (Regis, 1989, p. 415). They inhabit the Districts of Ranau, Tambunan, Kota Belud, Penampang and Papar. There are dialectal and cultural variations across these areas. Those from 
Tambunan District, number around 33,000 (based on 2008 District Office figures and allowing for 10\% increase). The Rungus are the second largest Dusunic group with a total population of 120,000 to 150,000 (Porodong, 2012, p. 111). They are the original ancient inhabitants of the Kudat Peninsula in northern Sabah. Around 150 years ago, a group migrated east to the Bengkoka Peninsula (part of today's Pitas District). Today, some mixed Rungus villages are also dispersed across Kota Marudu District among the Kimaragang Dusun and other groups there. The Lotud number around 20,000 and are the main ethnic group of Tuaran District (Ethnologue $\left.{ }^{\circledR}, 2016\right)$.

I first heard about the sundatang while visiting my husband's village, $\mathrm{Kg}$. Karanaan ${ }^{3}$ of the inland upland Tambunan District in 1977. This was a short three-month trip for a moginakan family feast in honour of our marriage in 1976 in Australia. The instrument was said to be quite rare and many people claimed they had never seen one. Later after returning to live in Sabah in 1982, I was able to study this sundatang, as well as other instruments from Tambunan and the music associated with these. Over the years, I have undertaken deeper research among many other local cultures. Recently, I have re-examined and updated some of my earlier findings on the structure and nomenclature for parts of the Tambunan sundatang.

Gleaned from decades of ongoing ethnomusicological research in Sabah, this article compares the Kadazan Dusun sundatang from Tambunan, with the Rungus sundatang and the Lotud gagayan. It seeks to answer the following questions. What are the differences in structure, performance practice and context between the three main types of boat lutes played in their respective Dusunic cultures of Sabah? What are the characteristics of their music? Are there organological relationships between these lutes and those of surrounding regions? And finally, what is the status of these performance genres in Sabah today?

\section{The Kadazan Dusun Sundatang from Tambunan}

The sundatang of the Kadazan Dusun from Tambunan has a small, somewhat diamond-shaped or oval body with a neck of over a metre long. It is made from jackfruit tree woods, either nangko (Artocarpus integer; Malay nangka) or timadang (Artocarpus odorartissimus; Malay tarap). During construction, the front is hollowed out, then covered by a thin piece of wood with a bridge and a "nose" or stringholder. ${ }^{4}$ The rounded tapered tuning pegs for the two strings are inserted diagonally into either side of the pegbox that is an extension of the neck. The lower part of the body is carved into a large thick "tail". Of the two strings, the lower pitched one on the viewer's left is made from wire (formerly brass), while the other one on the viewer's right nowadays is made from nylon string (formerly giman root, botanical classification undefined). The latter is affixed to the neck roughly halfway along its length with a small lump of beeswax (sopihut or sopinit). Four to seven frets of thin cane or tuai (Calamus javensis), that has been cut crosswise, are gummed to the neck with beeswax under this string below this lump. The other, longer string has no frets below it, and its sound functions as a drone in the sundatang music.

During performance, the musician sits holding the sundatang vertically or tilted slightly to his or her left, with the tail at the lower end of its body supported under the right thigh. The performer strums and plucks the strings across the front of the body with the fingers of the right hand, while the fingers of the left hand stop and unstop the fretted string on the right (Figure 2).

Madam Kimoi, now 88 years old, of $\mathrm{Kg}$. Timbou (not far from Kg. Karanaan) is among the last sundatang performers in Tambunan. She inherited her sundatang from her father. It is made from light coloured nangko, the common jackfruit tree wood. The front of the instrument is also a piece of nangko that was glued to the body with sopihut. According to Kimoi, the neck of the sundatang was originally much longer, but the instrument was broken when someone grabbed it to hit a dog that had entered the house when she was a child. Her father repaired the instrument, but the neck is shorter than it was originally and there is now a joint that can be seen on the front below the frets and higher up across its back. There are also only four frets on the front (Figure 3a and Figure 3b). 


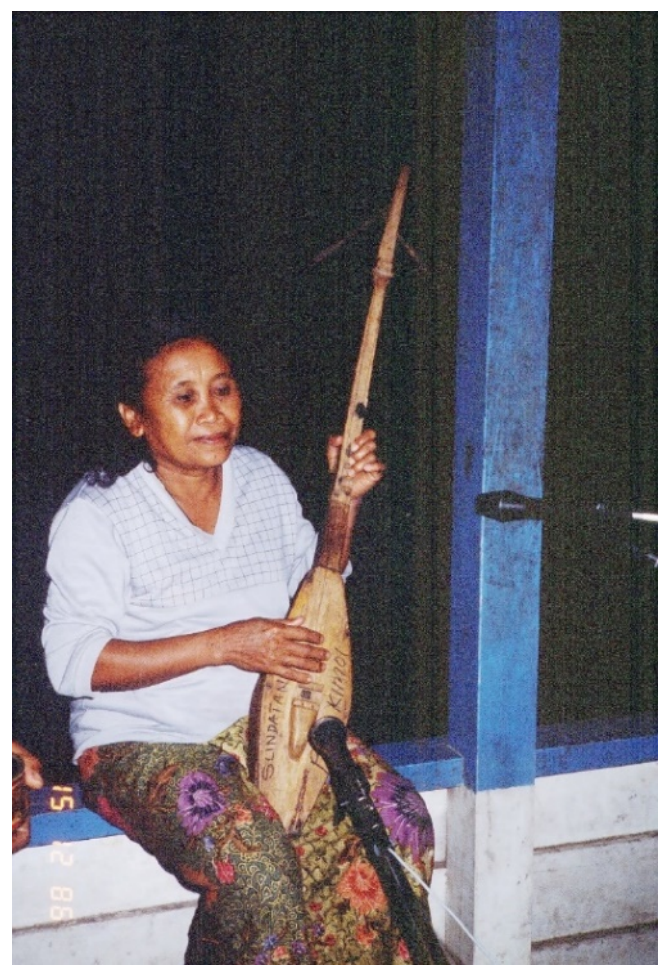

Figure 2. Madam Kimoi (then around 54 years) of Kg. Timbou, Tambunan playing her father's sundatang. (Source: Jacqueline Pugh-Kitingan, 15 December 1986)

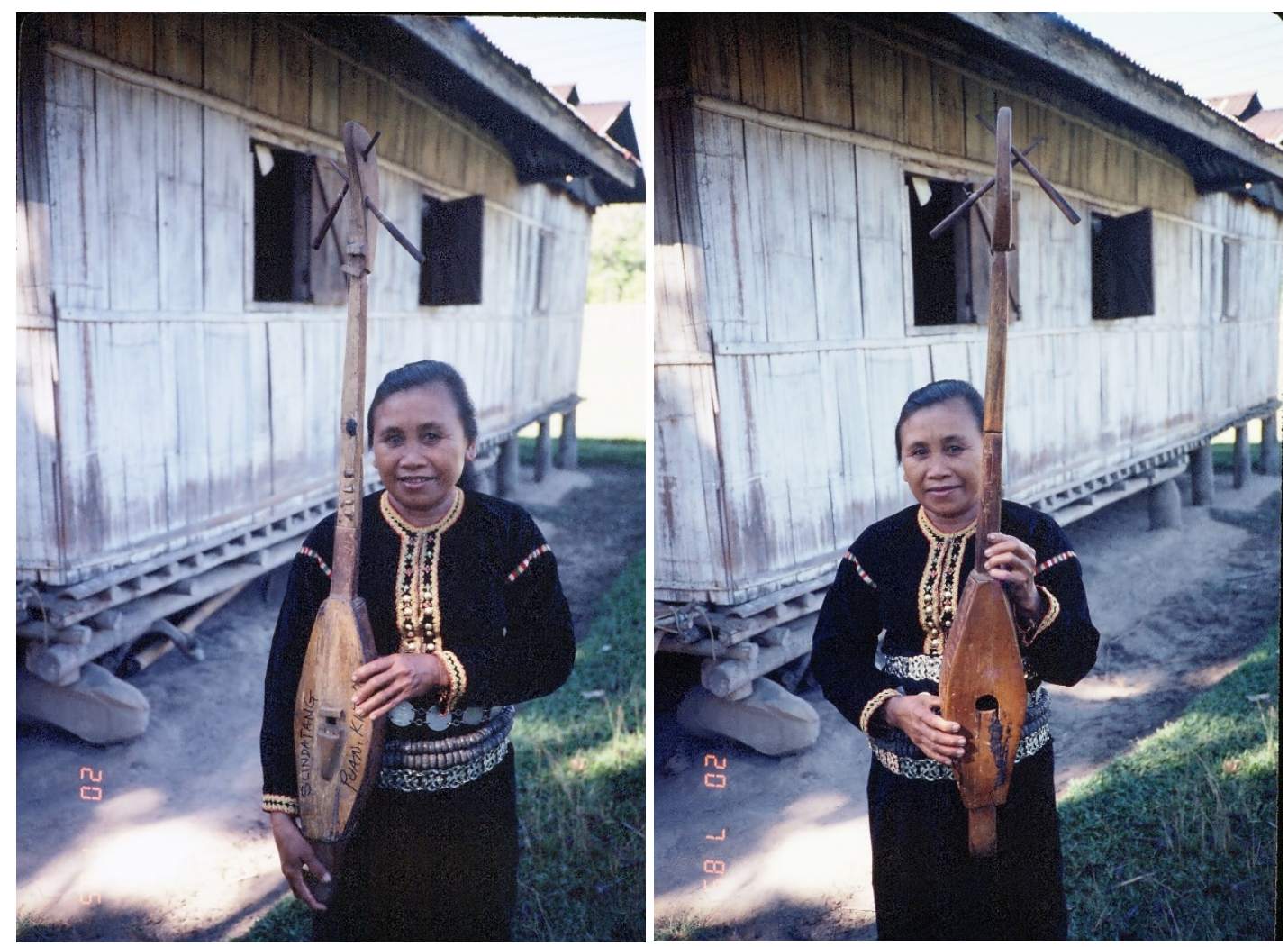

Figure $3 a$ (left) Madam Kimoi, then aged around 53, showing the front and Figure $3 b$ (right) back of her sundatang. (Source: Jacqueline Pugh-Kitingan, 20 July 1985) 
Kimoi's nomenclature for the parts of her sundatang is a mixture of terms for body parts, functional words and, for the strings and frets, the materials from which they are made (Figure 4). She refers to the pegbox at the top of the instrument as timbok, the term for a lady's hair bun, while she calls each of the tuning-pegs pongisusan, "the place that you turn" referring to the turning action of tightening the strings on the pegs. Each string is wound onto its peg, which is then inserted into the pegbox. The strings are collectively called pongombitan ("the place that you pluck"), but are individually named according to the materials from which they are made. Thus, the longer string on the viewer's left is called kawot (that Kimoi pronounces as kawat), which refers to brass or metal wire and also conveys the idea of tightening or tuning. The shorter string on the viewer's right was traditionally made from the root of the giman plant and hence was named giman. Nowadays, she uses thin nylon fishing line or tansi for this string, and thus calls it tansi (some say tangsi).

Kimoi refers to the soundbox as the tinan or "body" of the instrument. It has a large hole at the back and a smaller hole on the front between the pinonodu (wedge) or bridge, and the stringholder, the comparatively short todung sundatang or "nose" of the sundatang. The base of the tinan extends into a large thick tikiu or "tail" that supports the instrument under her right thigh during performance. ${ }^{5}$

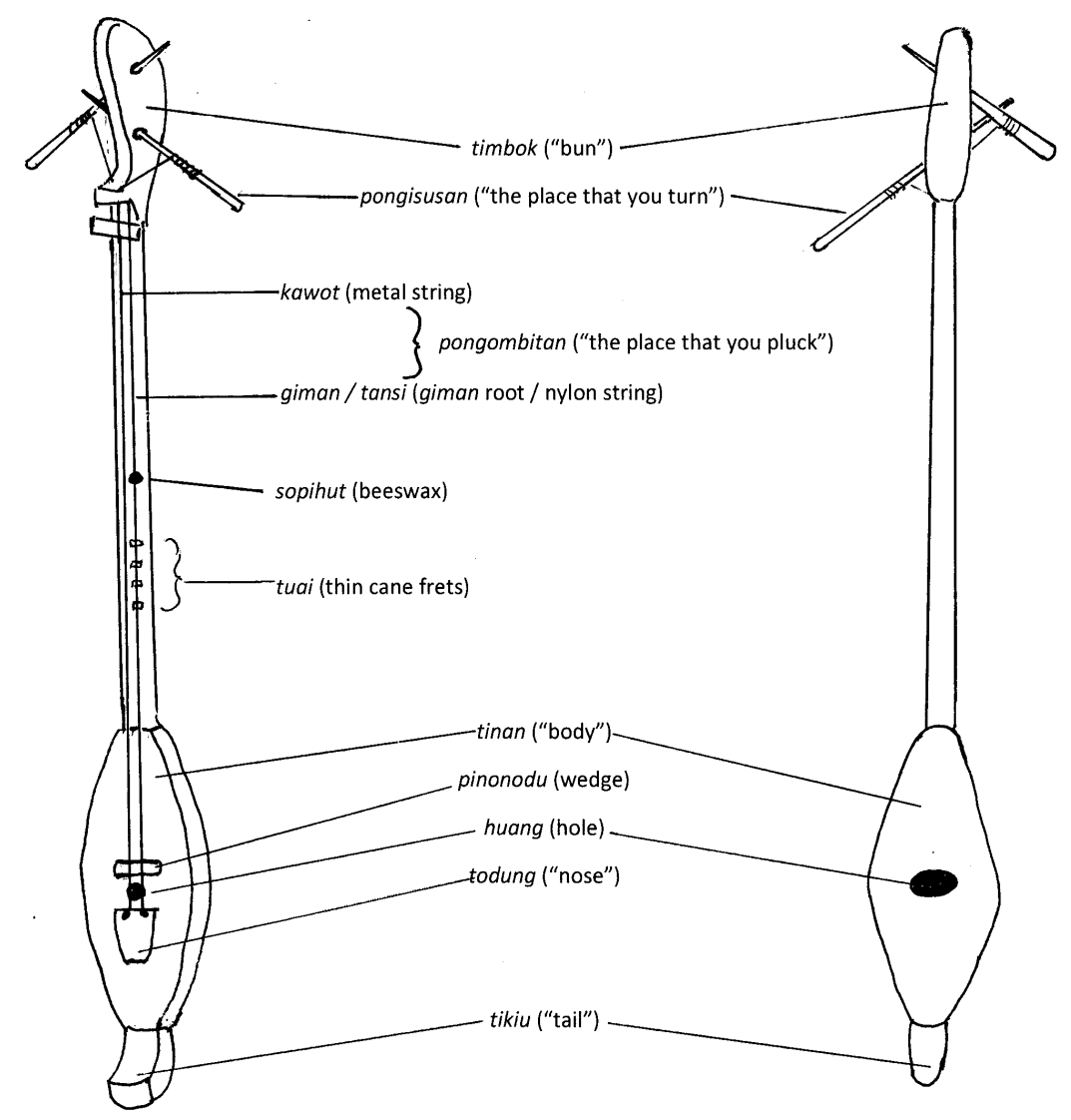

Figure 4. The Kadazan Dusun sundatang from Tambunan with Kimoi's labels. (Source: Jacqueline Pugh-Kitingan, 30 November 2020) 
During 1987, I was able to interview the late Unsud bin Masigi of Kg. Karanaan, a sundatang player then around 63 years old, who had inherited his instrument from his ancestors as far back as six generations before. This had a similar structure to that of Kimoi's sundatang, but it had a long neck measuring 122 centimetres. The instrument was made from a single trunk of dark-coloured sturdy lugu timadang or core of the timadang (Malay: tarap) a jackfruit tree from the forest. The body had been hollowed out from the front, and the front face was made from lighter-coloured nangko wood. The original tuning pegs had disintegrated, so Unsud had replaced them with rectangular pieces of nangko wood (Figure 5).

Unsud labelled the parts of his sundatang using similar terminology to that of Kimoi. However, he called the pegbox at the top of the instrument tuhu or "head," and the tuning pegs were each named pongiruson "the place that you tune" referring to tuning the strings. He called the neck tinggayan "the place that can be held".

There were seven groups of six notches each cut along each side of the neck from just below the pegbox. Unsud explained that six of these groups were carved consecutively by his ancestors one after the other who had learned to play the instrument, and each notch represented one year that a particular ancestor took to practice playing the sundatang until they were proficient (a year was estimated according to one padi-planting and harvesting cycle). Unsud had also carved the last group of notches as a record of his years of practice. Each performer played the instrument throughout his life, then it would be taken up by one of his children when he was too old to play. This indicates that Unsud's sundatang may be around 300 hundred years old. According to local legend, the ancestor who originally made the sundatang is said to have used the instrument to bash and kill a large bugang or flying eagle-like monster that was attacking and eating the people in the longhouse. ${ }^{6}$ Although Unsud knew who his ancestors were, he would not tell me their names in accordance with Tambunan traditional custom which forbids articulating the names of one's forebears in conversation.

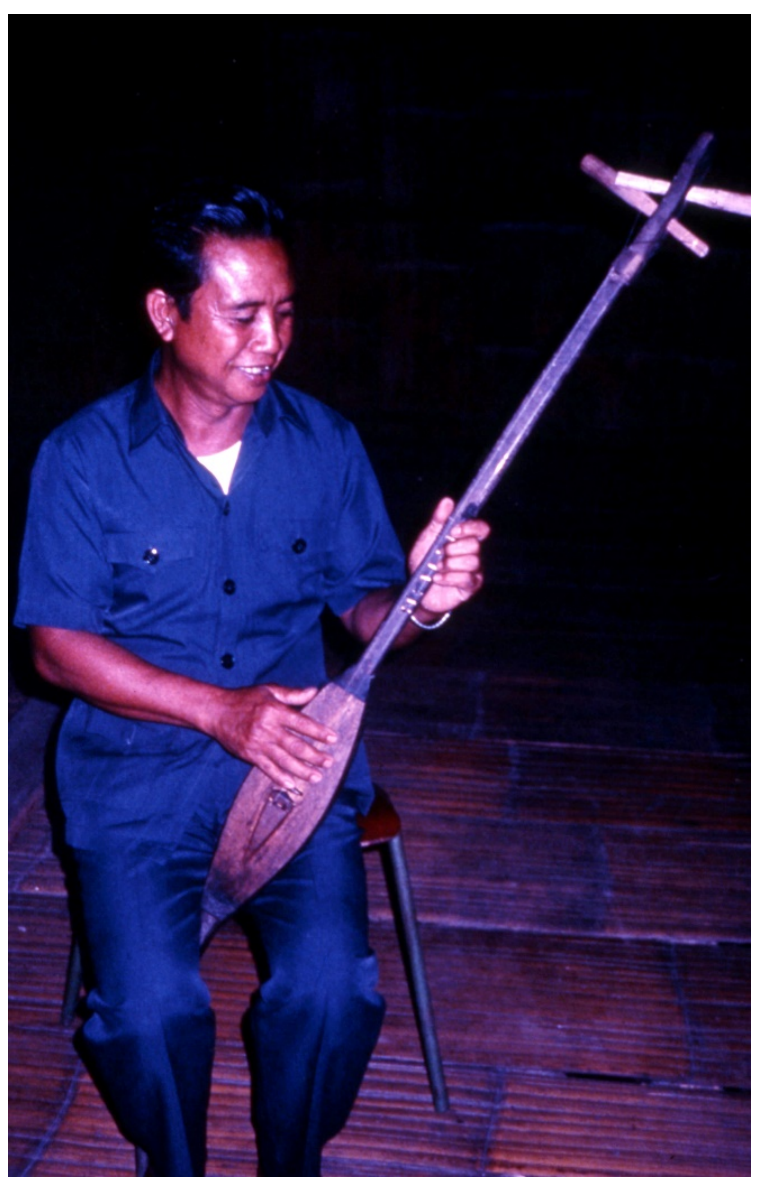

Figure 5. The late Unsud Masigi, around 63 years, with the sundatang inherited from his ancestors. (Source: Jacqueline Pugh-Kitingan, 19 December 1987) 
The Kadazan Dusun sundatang of Tambunan is traditionally performed for entertainment in the home. Its music imitates at a slower pace the patterns of tinondot, the music of the sopogandangan gong ensemble that consists of a hand-held gong called koritikon when it is played in the ensemble, seven hanging gongs of various kinds, and a single-headed drum. This ensemble accompanies dancing or magarang. Sometimes, the sundatang can be accompanied by another person beating the koritikon. This sundatang music accompanies the slow sedate magarang sundatang dance by a couple. In this case, the dancers move their feet flat on the floor; the man raises his arms and hands only to waist height, not shoulder height, and the woman raises her hands merely to hip height with her arms hanging outwards, not curved upwards. Although rarely performed today, the magarang sundatang is suited to dancing in a confined space such as a room, or private family apartment in a longhouse of the olden days.

An example from the start of a sundatang performance by Kimoi is shown in Figure 6. The syncopated rhythms are akin to the colotomic patterns of tinondot, but the pace of the music is much slower. The kawot sounds around a major $6^{\text {th }}$ below the open nylon or tansi string. The kawot forms a drone below the melodic patterns played on the higher pitched string. These patterns freely imitate the composite melodic structures of the gong ensemble music, but the rhythms of the music for dancing can still be heard. Kimoi said that the kawot string provides a distinctive ringing metallic sound that enhances the music. Unsud explained that the giman string was the leader in the music while the kawot merely emphasized the beat.

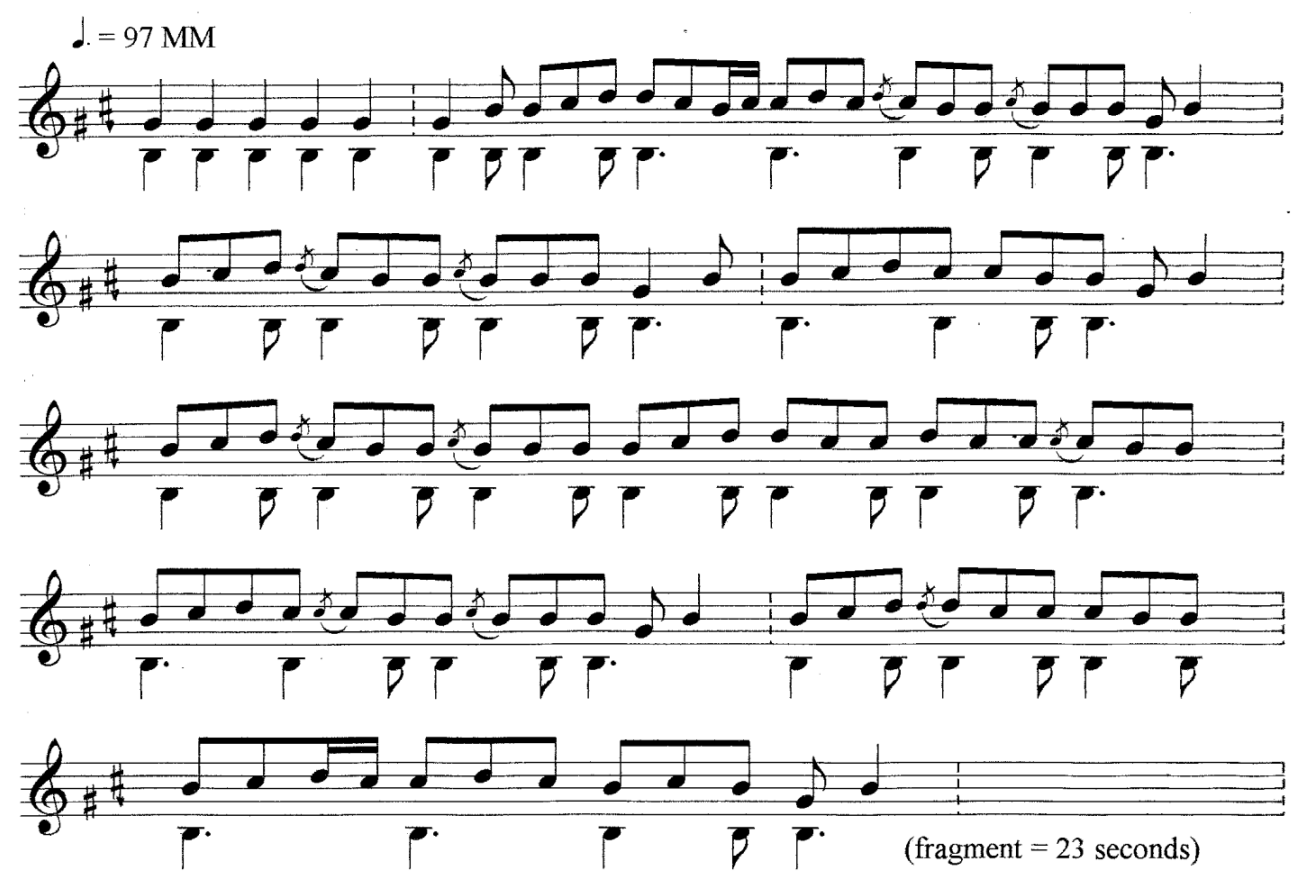

Pitches by ear

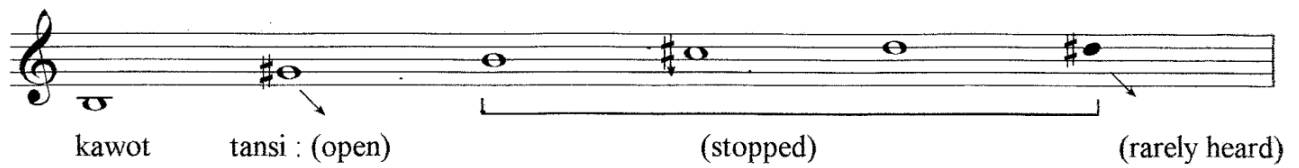

$\frac{H}{7}=$ sounds tone lower than written

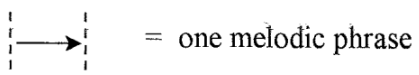

Figure 6. Excerpt from the start of a sundatang performance by Kimoi. (Source: Jacqueline PughKitingan, 1 March 1986) 
Figure 7 shows the basic colotomic pattern of tinondot by the sopogandangan ensemble from $\mathrm{Kg}$. Timbou and Kg. Karanaan. The koritikon is the small hand-held knobbed gong, while the karatung is a single-headed native drum with tuning pegs around its head. The other instruments are various kinds of hanging gongs, and each of these names denotes the rhythmic pattern that each instrument plays. Each part combines to form vibrant rhythmic music that accompanies dancing in both social ceremonial contexts (Pugh-Kitingan, 1988, pp. 26-27, 35, 43-45, 54-56; 2003, pp. 4-11, 35-37).

Here, the pitches shown beside the instrument names indicate the most audible frequencies in the timbre of each instrument, while the time signatures provide an approximation of the basic beat. The gongs labelled koritikon, bobogon, kuribadon, and kutoukutowon are generically called sanang in Kadazan Dusun. They are smallish thick brass gongs of various sizes, each with a flat face around the boss and a back diameter that is much smaller than the front. The tagung tatahis ("high-pitched tagung") and tagung tohombou ("low-pitched tagung") are large, thin, narrow-sided, brass gongs, generically called tagung, each with a raised ridge around the boss and back and front diameters of the same size. The tongtoongon and tawag are generically labelled tawag and are large, heavy, deep-sided brass or bronze gongs, each with a raised ridge around its large boss, and a back diameter that is much smaller than the front. Here, the instruments are shown in order of their physical position in the ensemble. Musically, however, the instruments enter koritikon, karatung, bobogon, kuribadon, kutoukutowon, then the two interlocking tagung, followed by the two tawag. An individual gong is known by its generic name until it is included in the ensemble. Then it takes on the specific musical name of the part that it plays.

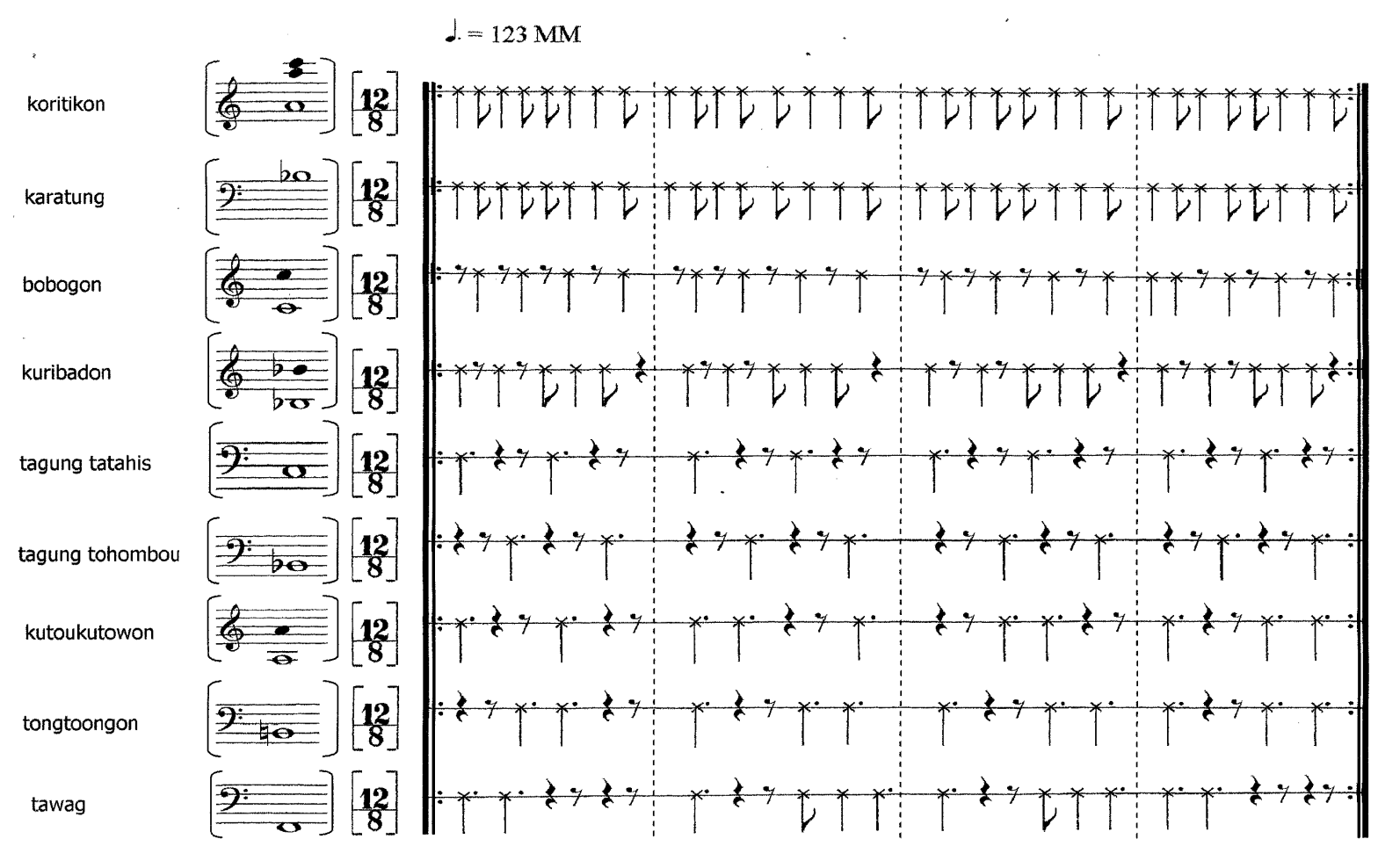

Figure 7. Basic colotomic pattern of tinondot or music of the sopogamdangan ensemble. (Source: Jacqueline Pugh-Kitingan, 23 March 2012)

A comparison between Figures 6 and 7 shows that although the pace of the sundatang music is much slower than tinondot, its syncopated beat reflects that of the gong ensemble performance. The rhythmic patterns of the drone string recall the dominant beat of the koritikon and karatung, while the melodic patterns of the upper string somewhat resemble the colotomic patterns of the hanging gongs. 


\section{The Rungus Sundatang from Kudat}

Unlike the lute from Tambunan, the sundatang of the Rungus of Kudat District is always a man's solo instrument played for personal expression or to entertain children and others in the longhouse. Rungus women prefer to play the turali noseflute. As shown previously in the turali example from $\mathrm{Kg}$. Bavanggazo, Kudat, young women who were novice bobolizan (priestesses) in the traditional Rungus religion used the turali to help them memorise rinait, the long sacred ritual poetry (Pugh-Kitingan, 2017, pp. 15-28). Although they were prohibited from chanting rinait outside of ritual contexts, they could softly blow the tunes of the chants with the turali. Over time, women developed secular turali performance that freely imitates the melodies of chants. The turali is thus a woman's instrument among the Rungus, while men prefer sundatang.

An example of a Rungus sundatang is that of Mogowan bin Malis, now around 64 years, from $\mathrm{Kg}$. Gombizau, Kudat, located not far from Kg. Bavanggazo. It is made from nangko wood (Figure 8). Structurally this instrument has a deeper somewhat squarish soundbox, compared to the sundatang from Tambunan, and has a comparatively shorter neck. Mogowan refers to this neck in the Rungus language as randagan ("handle"), which conveys a similar meaning to tinggayan in Kadazan Dusun. The front face of the body has a pattern of small holes above the stringholder, but there is no bridge. The stringholder is longer and narrower than that of the Tambunan sundatang, and extends down to the end of the front. This sundatang sometimes has a small thin carving at its lower end, but lacks the large protruding tail at the base of the body that is part of the Tambunan sundatang.

When making a Rungus sundatang, the body of the instrument is hollowed out from the back. Its strings are inserted into the two holes in the stringholder on the front, and also through two holes in the pegbox. Each then exits through a hole in the pegbox to be wound onto a tuning peg. After the strings are inserted, the back is covered by two thin layers of wood that are stitched with string or wire at one end and gummed to the body (Figure 9). Both strings or hontol are made from wire (formerly brass). Unlike the sundatang from Tambunan, each tuning peg is inserted at right angles into the pegbox and then its short protruding end winds up the string. Its frets or ulob are chips of bamboo or cane, each mounted vertically under the higher-pitched string in a mound of beeswax. This higher-pitched string, on the lower front side of the neck when played, is stuck to the neck by a lapazan or fixed fret. Below this there are five $u l o b$, two (or sometimes three) on the upper part of the body, and the others along the lower part of the neck.

In addition to functional terms in the Rungus language, Mogowan uses anthropomorphic body parts terminology for most the sections of his sundatang (Figure 10). Thus, the soundbox is labelled inan ("body"), its tiny tail at the end end is busul ("bottom" or "buttocks"), the front face is kangkab ("chest"), and the sections at the top of the inan on either side of the randagan are its kazab ("shoulders"). Its inner back layer is called likud ("back"), and this is covered by the outer atob or cover. The long stringholder on the front of the kangkab is called the todung ("nose") of the sundatang, while the pegbox below the carving at the other end of the randagan is the ulu ("head") and the two tuning pegs are its tohingo ("ears"). The ulu or pegbox extends into a carved decoration or biningkoko. 


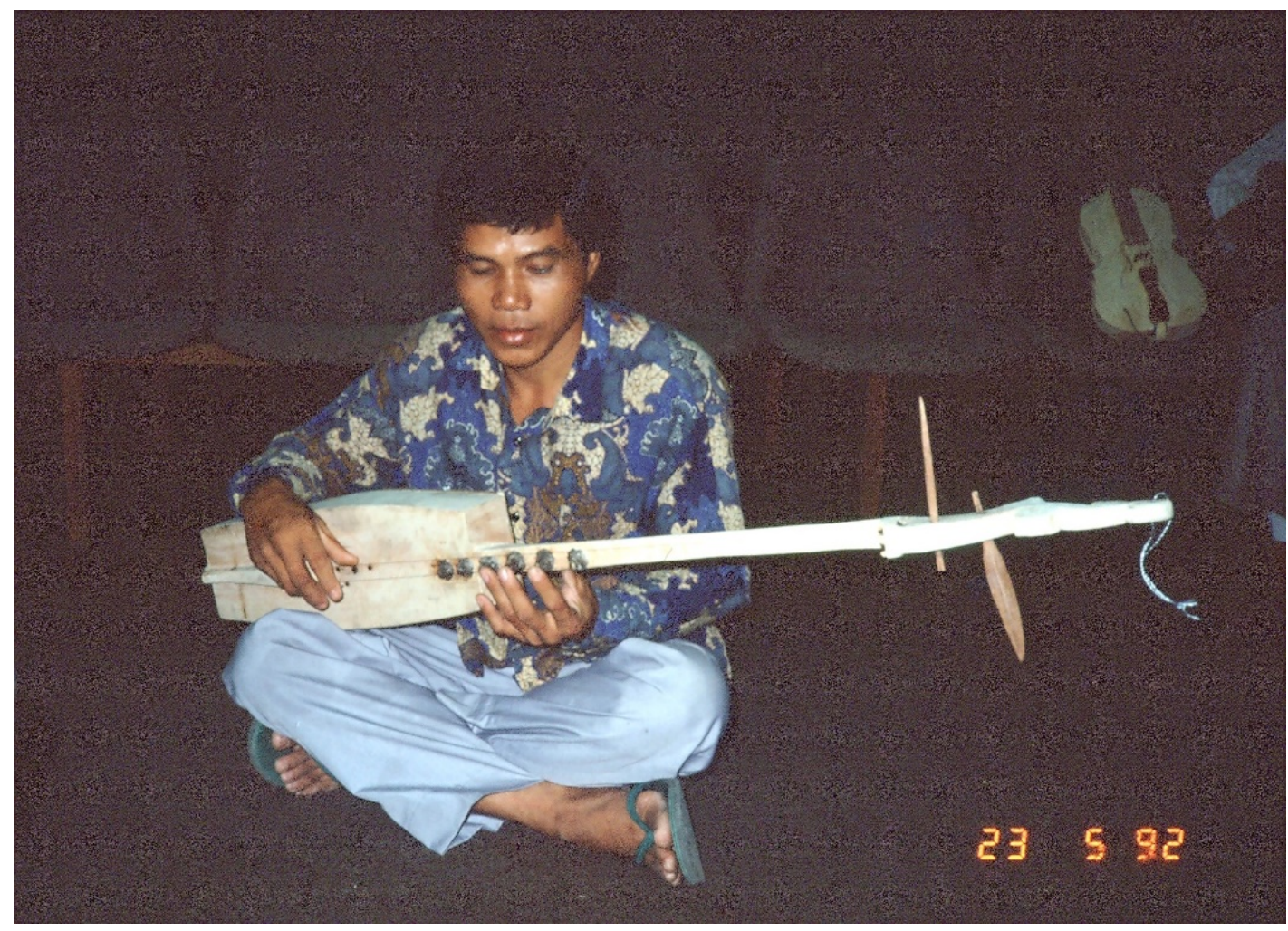

Figure 8. Mogowan from Kg. Gombizau, Kudat playing sundatang. (Source: Jacqueline PughKitingan, 23 May 1992)

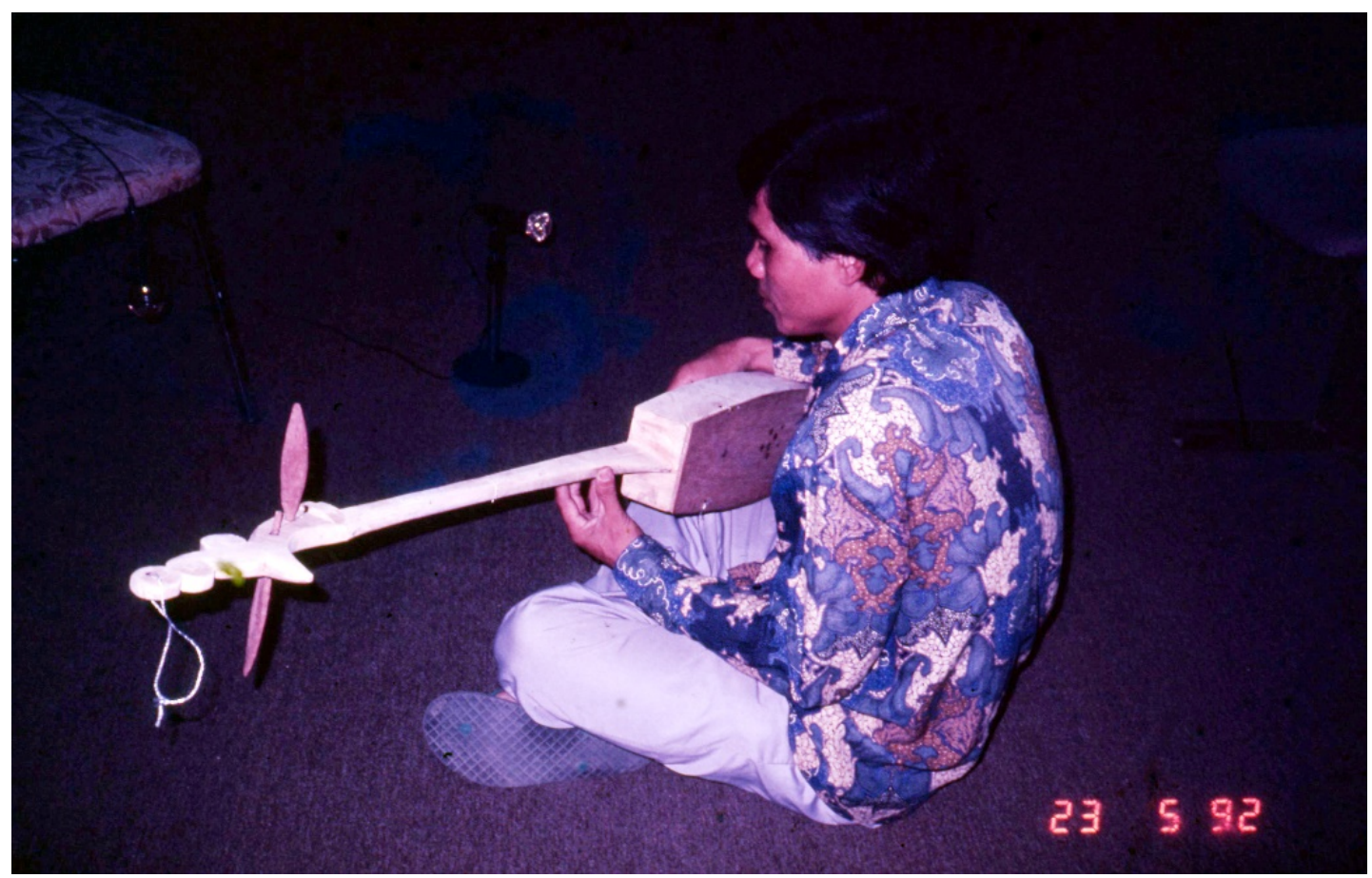

Figure 9. Rear view of Mogowan playing the sundatang showing its back and tuning pegs. (Source: Jacqueline Pugh-Kitingan, 23 May 1992) 


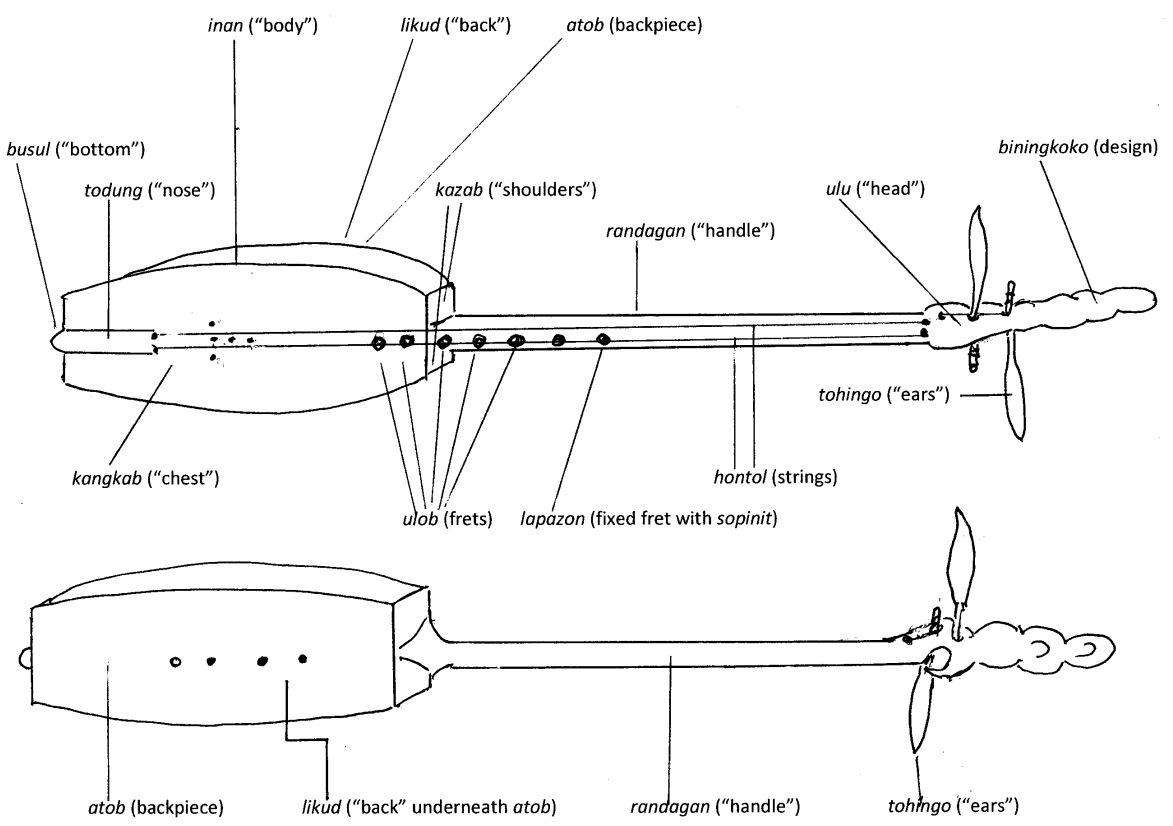

Figure 10. The Rungus sundatang using Mogowan's labels. (Source: Jacqueline Pugh-Kitingan, 30 November 2020)

Unlike the sundatang from Tambunan, however, this instrument is held horizontally in the lap with the neck pointing to the player's left like a guitar, and the fretted string is plucked with the nail of the little finger of the right hand while the thumb plays the unfretted string as shown in Figure 8. The soft-sounding music of the sundatang can imitate various Rungus songs, and also the Rungus pongigalan or gong ensemble music for accompanying mongigol (Rungus dancing). In pieces that imitate pongigalan, the performer will periodically knock his right forefinger on the kangkab above the strings to freely suggest the tontog or single-headed drum that is played with the hanging gongs. This performance is to entertain children and others in the longhouse.

There is not room here to give a detailed discussion of Rungus sundatang music. A fragment of a performance by Mogowan, then aged around 36 years, is transcribed in Figure 11. The music in this example freely imitates the traditional Rungus song called "Mamaranggi". 

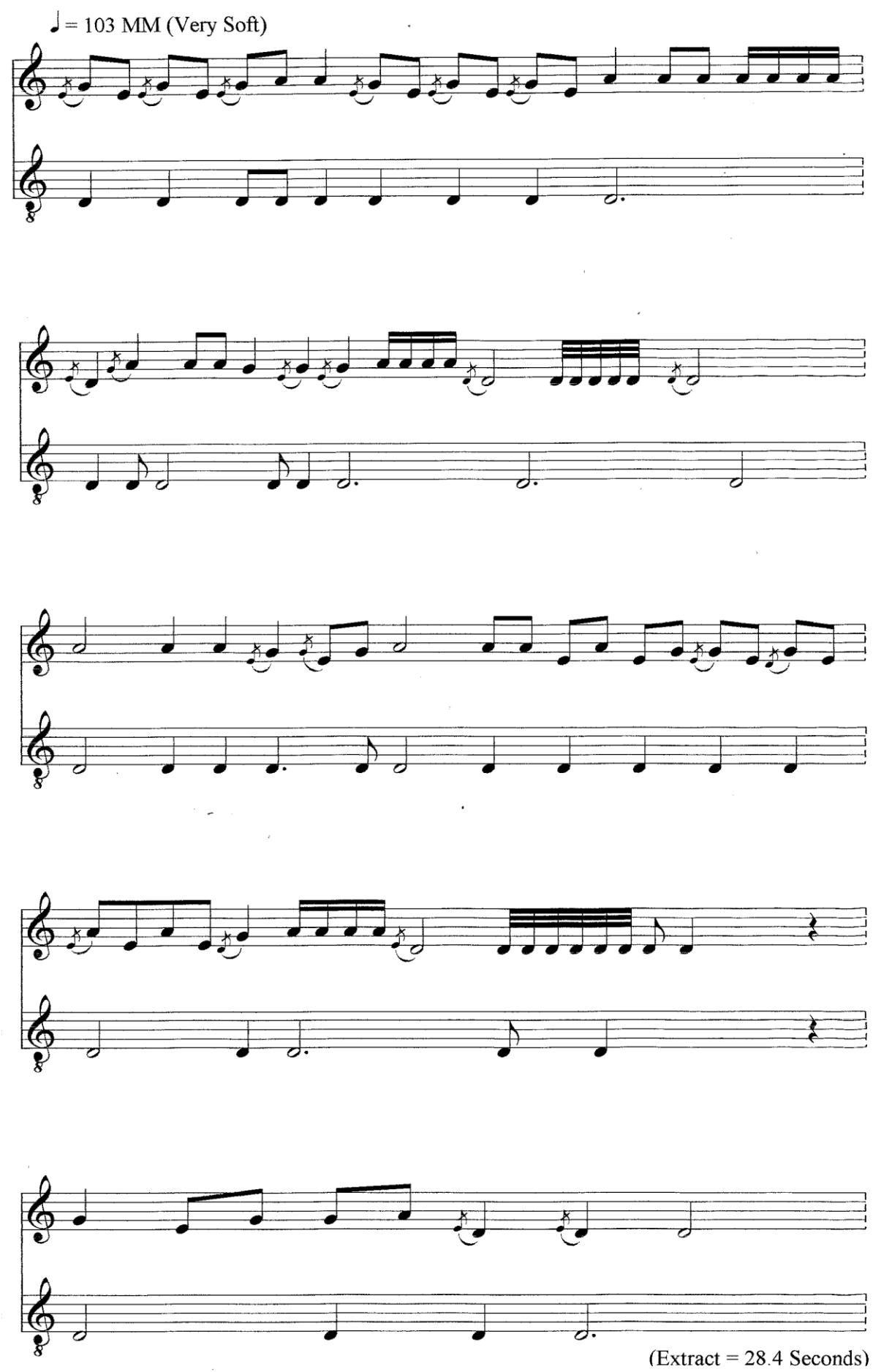

Pitches by ear

Fretted String

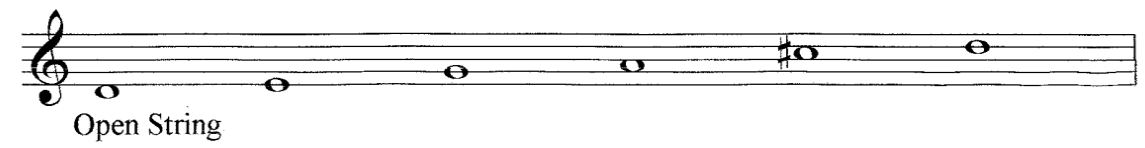

Unfretted String 7 :

Figure 11. Excerpt from the start of a sundatang performance imitating a song Mamaranggi, by Mogowan (Source: Jacqueline Pugh-Kitingan, 2 July 2020) 
As shown here, the pitch of the unfretted string sounds an octave below that of the open fretted string. This music is very soft, and its overall sound is dominated by the sonorous drone of the unfretted string that is played with the right thumb. In this short excerpt, the performer does not use the two highest pitches of the fretted string. The music is characterised by recurring grace notes and occasional semiquaver and demisemiquaver-like motifs. The latter are extremely soft, and are produced as the performer rapidly plucks the higher-pitched string, with the nail of the little finger of the right hand.

The soft but penetrating sound of the Rungus sundatang can be heard throughout the longhouse, even in private family apartments at the farthest end of the building. When played at night, it has a soothing effect that is said to help children settle down to sleep.

\section{The Lotud Gagayan from Tuaran}

Like the Rungus sundatang, the gagayan lute of the Lotud from Tuaran District of Sabah is traditionally a man's instrument, while women prefer to play the turali. As shown previously in the discussion of turali from Kg. Dungang, Tuaran, women play two sizes of noseflute to copy the tunes of secular songs for entertainment (Pugh-Kitingan, 2017, pp. 19-22). The gagayan, however, is a large, loud instrument that was considered too heavy and cumbersome for a woman to comfortably play. It is much larger than the Kadazan Dusun and Rungus lutes, and is held horizontally in the lap pointing to the player's left like the Rungus sundatang, but is supported by a cord worn around the performer's neck. Traditionally, gagayan were often played in duets (batangkung).

The late Liput bin Enah and the late Tombung bin Ambing of Kg. Tutu often played their gagayan together in batangkung (Figure 12). Each instrument was made from nangko, described as kulipapo or softwood, but timadang could also be used for making a gagayan. Tombung's instrument had a dark brown colour and appeared to be much older than that of Liput.

Like the Rungus sundatang but unlike the sundatang from Tambunan, each gagayan lacked a bridge on their fronts. They had been hollowed out from the back during construction, and the open back was covered by two layers of thin wood as tutub ("covers"). The outer layer of the tutub had a large carved hole or ruang ("space") in the middle. The ruang on Tombung's gagayan was heartshaped, while that of Liput was oval-shaped. These two layers of thin wood were gummed into the frame of the hollowed out back of the gagayan. They were not stitched to the body with metal wire, like the Rungus sundatang (Figure 13).

Both musicians used similar terminology for the parts of their gagayan (Figure 14). The large, deep, somewhat rectangular soundbox is called inan ("body"), while the long stringholder is the odung ("nose"). The two brass strings or obuk enter this at the front of the body, as on the Kadazan Dusun and Rungus sundatang, but are wound across the front of the odung through a series of small holes on either side. Above the odung, the front of the inan features a series of tiny resonance holes or lobu that form a triangular shape. At the end of the inan, each instrument has the carving of the shape of an animal head. Liput's very large gagayan has the head of a horse or kuda, while that of Tombung's has the head of a deer or binanjou. 


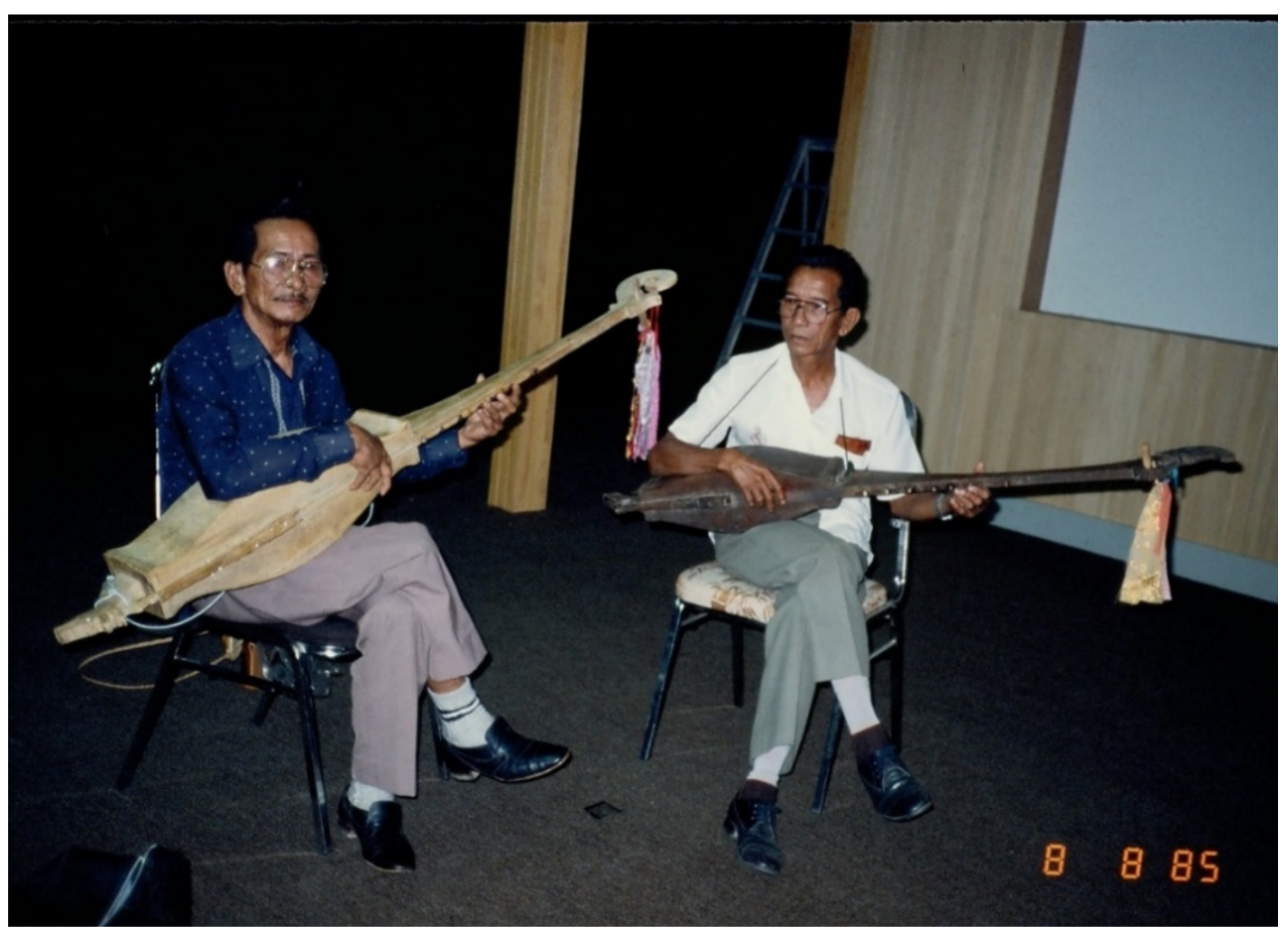

Figure 12. Liput (left, 60 years) and Tombung (55 years) playing their gagayan in batangkung (duet). (Source: Jacqueline Pugh-Kitingan, 8 August 1985)

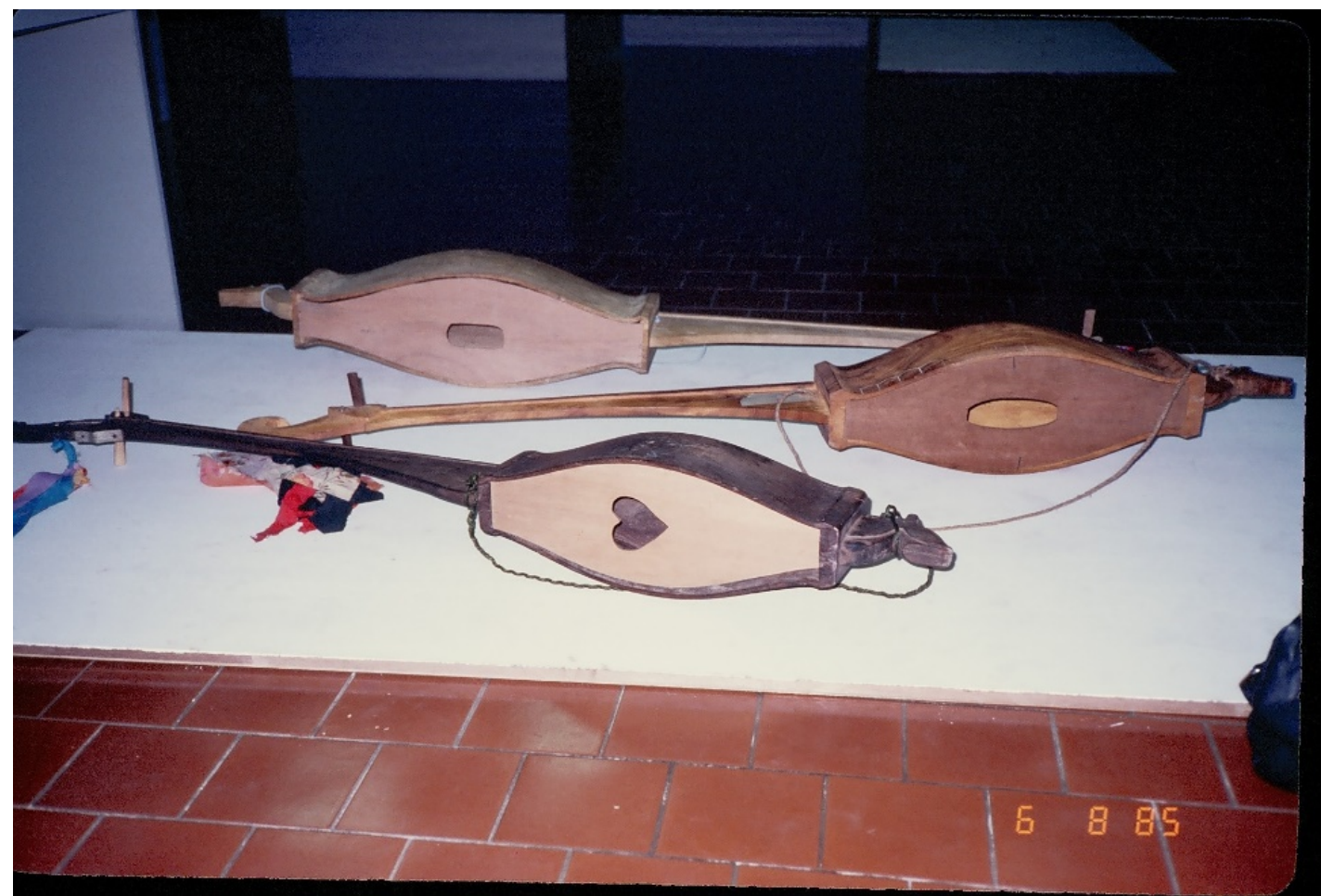

Figure 13. A rear view of three gagayan showing their double-layered back covers (Source: Jacqueline Pugh-Kitingan, 6 August 1985) 
The long, thick neck of the gagayan is named tonok or "calf" (leg), and the pegbox extends into carved design called a $k u k u$ or "tail". The kuku on Tombung's gagayan is carved into the shape of a deer's tail, while that of Liput has a curled shape like a horse's tail. A decorative cloth or wiriwiri is hung from the $k u k u$.

These gagayan have two metal strings called obuk, and the string on the bottom, when held in a playing position, is stuck halfway along the tonok with a piece of beeswax gum or tukod. Six thin cane frets or soludon are stuck flat against its long neck under the inner string below the tukod, like the frets on the Tambunan sundatang. There is a cut-out section on the front of the pegbox where the strings enter. Each tuning peg turns the strings inside the pegbox. The tuning pegs are called simbong ("earrings"), because they stick out perpendicular to the pegbox like a pair of woman's earrings.

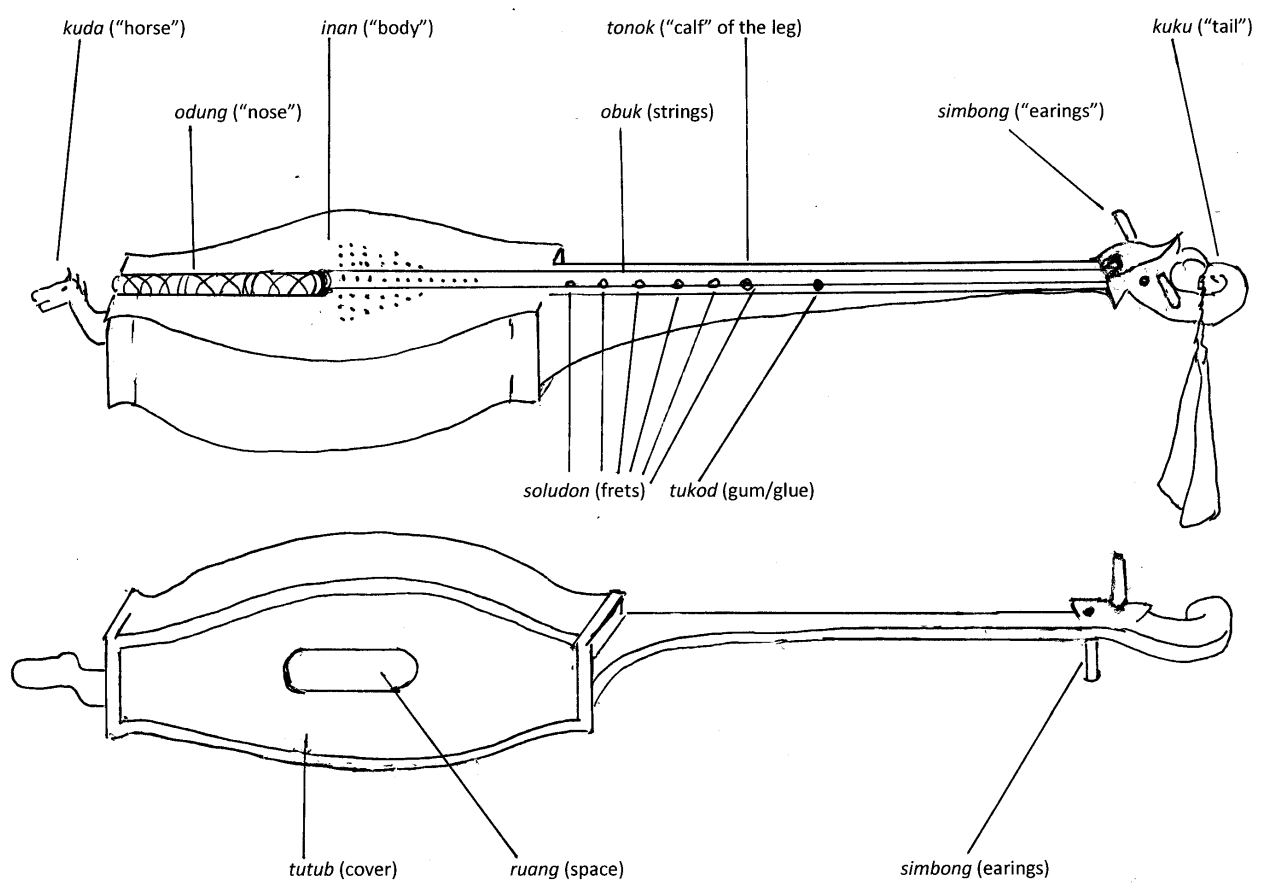

Figure 14. The structure of Liput's gagayan (Source: Jacqueline Pugh-Kitingan, 30 November 2020)

Essentially the same terminology for the parts of their instruments was used by the late Reja bin Ambayang of Kg. Dungang and the late KK Lintar bin Ugau (then both in their late 50s) whom I recorded playing their gagayan duet at Kg. Tutu Solupuh in January 1996. Reja and Lintar, however, used the term kinuda for the pegbox and distinguished it from the kuku. The strings of their gagayan were also made from wire, but Lintar explained that in former times both strings were made from giman. Guitar wire has a louder, more brassy sound than giman root, and is more durable.

Gagayan performance was traditionally regarded as a highly esteemed art form, and was played in secular social contexts. The music produced was usually a free imitation of old traditional songs. These may be discerned from the recorded performances, but the melodic notation of batangkung defies detailed transcription. The instruments are deep-sounding, very loud, and each performer has his own particular tuning that produces a combined discordant texture in the duet. Figure 15 shows two recurring rhythmic motifs from the performance by Liput and Tombung. Strident variations of the first motif, alternated with overlapping triplet-like figures of the second. As in Reja's and Luntar's duet, the sounding of the two instruments was not always synchronous. Some passages are drowned out, especially in episodes with rapid ornamental motifs that are not played together in time. The lowerpitched strings also dominate the timbre, making frequency differentiation difficult. 


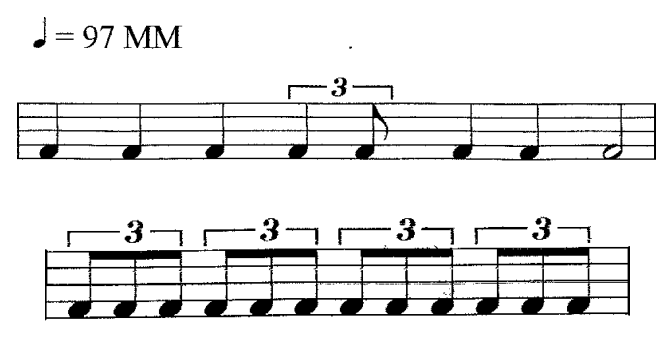

Figure 15. Recurring motifs in gagayan music

\section{Relationships with Boat Lutes from Surrounding Areas}

The Tobilung Dusun who inhabit the hilly area between northern Kota Belud and Kota Marudu Districts also play sundatang, as do the west coastal Kadazan of Penampang and Kinarut. The Kimaragang Dusun of Kota Marudu formerly played sundatang, but it appears that this instrument is no longer extant. These instruments were said to resemble the sundatang of the Rungus, being hollowed out from the back of the soundblox. The Tobilung instrument, however, had cane frets stuck flat against its neck and body. This instrument today has been modified with a guitar pegbox and six strings, of which four sound sympathetically below the two main strings. The rare coastal Kadazan sundatang has frets mounted in beeswax and tuning pegs inserted perpendicular to the pegbox. The sundatang is also found in a couple of villages among the Dusun in Ranau District in the interior of Sabah to the northeast of Tambunan District (Johan Adam Kitingan, personal communication, 30 June 2020).

The Labuk Dusun (also known as Labuk-Kinabatangan Kadazan or Eastern Kadazan) of Beluran District also have a lute called sundatang. This instrument, however, resembles a long gambus lute with a large bulbous soundbox that is hollowed out from the front and covered with thin wood or goat skin. It has six strings. Although this instrument indicates diffusion from contact with east coastal Muslim communities, it plays music in the same social contexts as the older sundatang instruments of Sabah (Alut, 1991, pp. 26,102).

Apart from the Dusunic instruments discussed above, boat lutes were also found among other cultures in Sabah. The Iranun of Kota Belud District (formerly Tempasuk) on the west coast of Sabah, a former maritime people of the Danao Language Family, also played a kudiapi that is no longer extant but is said to have resembled some of the Maranao kutiyapi from Mindanao (Brandeis, 2012; 2019, pp. 27-28). The Iranun and Maranao speak related Danao languages and have close historical connections. As mentioned above, Sabah's boat lutes are quite different from the sape types of Sarawak and Kalimantan further south in Borneo that have short necks, larger rectangular bodies and varying numbers of strings (Matusky, 1986, pp. 188-189; Matusky \& Tan, 2017, pp. 286-287). It is possible that Dusunic lutes in Sabah may have either developed through coastal trade with the Iranun, or that the Iranun may have acquired indigenous lutes from Dusunic peoples in northern Borneo and spread them through trade into the wider southeast Asian region.

It is not known when the Iranun first settled in northern Borneo, but they were already present on the coast of Tempasuk before the arrival of Maranao refugees fleeing volcanic eruptions in Mindanao from before 1667 and around 1765 (Warren, 1981, pp. 149-150; 2002, pp. 45-47). Linguistically, Sabah Iranun predates Maranao (McKaughan, 1996; Smith, 2011, pp. 5-6). In previous centuries, Sabah's Iranun were metallurgists and major maritime traders of slaves, brassware, textiles, horses and other goods across southeast Asia under the Brunei Empire and later (Gowing, 1987, pp. 150-160; PughKitingan, 2007).

From the $15^{\text {th }}$ to $17^{\text {th }}$ centuries, the Brunei Empire controlled Sarawak, all the coastal areas of northern Borneo (today's Sabah), and parts of the Philippines as far north as Manila (Bala, 2005; Warren 2002, p. 20, pp. 33-34). The Iranun of northern Borneo formed important linkages between Brunei other peoples throughout the region. In Sabah, Iranun trading posts were located at river mouths along the west coast from Mengkabong in Tuaran up to Indarasan in Kudat and also at Marudu Bay in northern Sabah, as well as at Tungku in today's Lahad Datu District on the east coast (Warren, 2002, pp. 126137). 
The Iranun have historical trading relationships with the Rungus of Kudat, the Kimaragang of Kota Marudu, the Dusun Tindal of Kota Belud (a branch of the Kadazan Dusun), and also the Lotud of Tuaran. Iranun culture strongly influenced that of the west coast Bajau, a member of the Sama' Family of Languages who were traditionally fishing communities along the shores of Tuaran and Kota Belud Districts. It appears, however, that the Bajau did not play boat lutes.

Dusunic peoples from the interior also periodically trekked over the Crocker Range to the west coast to trade their rice for salt with coastal communities, as well as gongs, brassware, woven headcloths and ceremonial textiles. Although they differ in culture and religion, individual Iranun traders sometimes formed dyadic "blood brother" relationships with their longstanding indigenous trading partners, especially among the Rungus and Lotud. The Rungus also acquired a rare embroidered headcloth through trade with the Suluk (Taosug) from the Philippines.

Hence, it is possible that certain kinds of long-necked boat lutes may have either spread from northern Borneo into the southern Philippines, or come into Sabah's indigenous cultures through sporadic maritime trade. Brandeis (2019, p. 49) states that the small box-like sundatang of the Rungus is the origin of the large box-like boat lutes of the Pala'wan of Palawan and the Higaonon of Mindanao. He attributes the presence of such lutes among this in the Philippines to trade under the Brunei Empire. During a visit to Puerto Princesa, Palawan in 1995, I saw many such boat lutes for sale in handicraft shops. They closely resembled the Rungus sundatang, but came in three sizes. The smallest from base to pegbox was the same size as the Rungus instrument, while the largest was up to a metre longer than the height of a man.

It should also be noted that the Bonggi, the indigenous people of Banggi and Balambangan Islands to the north of the Kudat Peninsula, speak a language of from Palawanic Family (Ethnologue ${ }^{\circledR}$, 2016). It is not known whether they played boat lutes, however, nor how much traditional contact they had with the Rungus.

Brandeis' extensive research on the Philippine boat lutes has identified and mapped 23 different types played in 37 indigenous cultures, encompassing the islands of Mindanao, Palawan and parts of Mindoro (Brandeis, 2017, pp. 36-37; 2019, pp. 17-24). Apart from connections with the Rungus sundatang, there are other structural similarities and differences between the Philippine boat lutes and the Sabah instruments. Brandeis notes that Philippine boat lutes are each carved from a solid log of wood and the body is usually hollowed out from the back then covered with a thin wooden board. This single board is often tied to the body by wire or string, or just nailed or glued, and has a sound hole or a pattern of little holes. Some lutes have carved animal heads at the ends of their bodies. Most have two strings - the fretted one plays melodies and is held fixed by a "zero fret", while the unfretted one plays a drone and provides rhythmic emphasis in the music. The two tuning pegs are round sticks with handles, inserted laterally into both sides of the pegbox. The Manobo lute, however, has obliquelyinserted tuning pegs that cross inside the pegbox. The stringholder on a Mindanao lute is very long and also functions as a bridge. On large boat lutes, the frets are chips of wood mounted in gum under the melodic string, and some frets may be glued to the front of the soundbox. The two strings are usually of the same material, either metal or formerly root. Mindanao lutes have a cut-out nut section at the peg box to support the strings (Brandeis, 2012, pp. 6-7; 2019, p. 8-10).

The Rungus sundatang and Lotud gagayan are somewhat similar to these, except that they have two layers of wood covering their backs. The two Rungus sundatang back boards are usually stitched at one end and glued to the body, while the gagayan resonance boards are both glued into the back of the instrument. The gagayan also has a horse or deer head carved at the end of the body and a carving of the animal's tail at the end of the pegbox. Horses are not normally part of Lotud culture, but they were significant in Iranun culture. The body shape of the gagayan, however, is different from most of the Philippine boat lutes. Both the Rungus sundatang and gagayan have somewhat box-like soundboxes, but the gagayan sides are more rounded than the Rungus sundatang. Apart from the Pala'wan and Higaonon instruments observed by Brandeis, it appears that the Philippine instruments lack the distinct shape demarcation between body and neck of the Sabah lutes (Rungus kazab or "shoulders").

Like the Philippine instruments, however, both lutes have two metal strings, and tuning pegs inserted at right angles to their pegboxes. The stringholders on the Rungus sundatang and Lotud 
gagayan each function as a bridge. The frets of the Rungus instrument are mounted vertically in beeswax, and the fretted string is held in place by a lump of beeswax (a "zero fret" in Brandeis' terminology). The strings on a Rungus sundatang enter the top of the neck through two small holes in the wood, and exit to be wound by the tuning pegs. The gagayan, however, has a cut-out nut section at the base of the pegbox that Brandeis noted on Philippine lutes, and the strings are turned for tuning inside the pegbox.

The Tambunan sundatang shares some similarities with these other lutes. The body, however, is hollowed out from the front. The instrument has a bridge on the front face, a short stringholder, two strings of different materials and diagonally inserted tuning pegs. The holes in its pegbox are unconnected, and the tuning pegs do not actually cross each other. During performance, it is held in an upright position, unlike the other two types that are held horizontally.

There are some similarities, however, in performance technique between the Sabah lutes and Philippine boat lutes. It appears that most of the Philippine instruments are held somewhat horizontally, like the Rungus sundatang and gagayan. While most Philippine instruments are played with a plectrum tied to the index finger of the strumming hand, the Pala'wan, Agusan Monobo and Subanen use their bare fingers (Brandeis, 2019, p. 61), as do the Kadazan Dusun and Lotud musicians. The Pala'wan use the fingernail of little finger of their right hand to pluck the fretted string (Ibid.) like the Rungus. In some Philippine performances, the musician may hit their thumb on the front of the body to copy the sound of a drum (Ibid.). As mentioned above, Rungus musicians also do this to imitate the tontog drum in pieces based on their gong ensemble music. These characteristics also support Brandeis belief that the Rungus sundatang is probably the origin of the Pala'wan and Higaonon instruments.

In terms of performance practice, the Philippine instruments are sometimes played solo for personal entertainment, while some may accompany dancing and others may be played with a tube zither or a drum (Brandeis, 2019, pp. 64-67). As shown above, the sundatang from Tambunan formerly accompanied the magarang sundatang dance and was occasionally played with a hand-held koritikon gong. Gagayan, however, were usually played in duet, while the Rungus sundatang was always solo.

Boat lutes are also played in Central and South Sulawesi. With the recent diaspora of Bugis people from southern Sulawesi into Tawau, especially from the 1960s onwards, the Bugis kecapi has come to Sabah. Like other boat lutes, this instrument has a long sleek body and two strings, but has a short neck. It is comparatively small and is held more or less horizontally, but its neck can point left or right according to preference, and is played with a plectrum. It is often performed in a group of two or three. It has become a significant feature of Bugis culture in Sabah, and is played solo or with other instruments during important social events (Daud, 2011).

\section{Current Status of the Sabah Genres}

In Tambunan, Kimoi has continued to perform her father's sundatang over the years. Recently while she was away on a short trip, however, some children playing around in her house found the sundatang, broke the strings, smashing its face, and losing its bridge and one of its tuning pegs in the process. This has caused considerable distress for Kimoi, and attempts are underway to repair the instrument.

Unsud passed away some decades ago. His brother Muja faithfully kept the old sundatang that was handed down over generations in their family, but the instrument is no longer played. It is believed that there is a spirit guarding the instrument, due to its great age. ${ }^{7}$

Meanwhile further south in Tambunan, Thadius Yongut, a renowned sompoton (mouthorgan) and suling (mouth flute) performer from Kg. Tikolod, has slowly been making a sundatang and intends to learn to play the instrument. The body of this instrument is also cut out from the front, like those of Unsud and Kimoi. Hopefully he will pass on this skill to younger generations.

The Rungus sundatang is still extant and continues to be played by middle-aged and elderly men as a pastime in many longhouses. The comparative continuing popularity of the sundatang among the Rungus may be largely due to the homestay tourism that has developed in several villages among the Rungus of Kudat, such as Kg. Bavanggazo where tourists come to experience Rungus culture and music.

Lotud gagayan performance was very common up to fifteen years ago, but today most performers have passed away. Only one very elderly musician remains, and he no longer plays the instrument. The rapid decline of the gagayan is largely due to a lack of interest by younger men, and 
the invasive presence of new digital media among youths, especially cellular telephones with games. Younger men who often work away from their home villages, lack the time and patience to develop the skill of gagayan performance.

\section{Conclusions}

Sabah's long-necked boat lutes are traditionally found in many Dusunic cultures, and constitute skilled artistic genres, being played in non-ritual contexts for entertainment. All three instruments discussed above are made from varieties of jackfruit tree wood, and have two strings with the lower-pitched string on the viewer's left and the higher-pitched one, that is affixed to the neck and has frets below, on the viewer's right.

The sundatang from Tambunan differs markedly from the other two boat lutes examined here. During construction, its body is hollowed out from the front, not the back like the other instruments. It has a bridge on the front of its body, and its frets are pieces of thin cane affixed flat against its neck. Its two strings are made from different materials - the deeper sounding one from wire (formerly brass), and the higher pitched from nylon string (formerly giman root). The tuning pegs are inserted into its pegbox at an angle, rather than at right angles to the neck like the other instruments. During performance, this sundatang is held upright, with its "tail" supported under the musician's right thigh. In Tambunan, both men and women can be sundatang players. This suggests that the sundatang genre from Tambunan represents a different tradition from those of the other two lutes, one that developed relatively independently in the interior of Sabah.

The Rungus sundatang and the Lotud gagayan are normally men's instruments. They are each constructed with the back hollowed out and covered by two layers of thin wood. While the gagayan has small cane frets stuck against its neck, the Rungus sundatang has its bamboo frets inserted vertically into mounds of beeswax under the higher-pitched string. The Rungus sundatang has a somewhat boxlike body, while the gagayan has more rounded sides. Both of these lutes are held horizontally in the lap like a guitar unlike the Tambunan instrument. Although the structures of their pegboxes are different, both lutes have their tuning pegs inserted at right angles to the pegboxes.

All three of the instruments discussed here use some anthropomorphic body parts terminology in labelling sections of their instruments. The two sundatang instruments identify the pegbox with head or parts of the head, and the base of the soundbox with a tail or buttocks. The gagayan, however, has the carving of the head of a deer or a horse at the end of its soundbox with the corresponding zoomorphic tail carved at the end of the pegbox. The neck is described as a calf (leg), however, and the tuning pegs as a woman's earrings.

It is clear from the indigenous nomenclature for the parts of these instruments that the western organological description of these lutes as "boat lutes" is culturally invalid. From indigenous perspectives, these lutes have nothing to do with boats. For the Kadazan Dusun and Rungus, the lutes are akin to a human form with the pegbox as the head, and the soundbox as the body. Apart from the designation of tuning pegs as "earrings", the Lotud gagayan presents a reversal of this form with the carved animal head at the end of the body, its carved tail and the end of the pegbox and a leg between body and tail. The three instruments vary in terms of their sound dynamics. The Rungus sundatang is very soft, while the gagayan is very loud especially when played in pairs.

The origins of these lutes in northern Borneo can only be postulated here. Clearly, they are part of a regional complex of such instruments throughout Borneo, the southern Philippines and parts of Sulawesi. The Sabah instruments, however, are structurally very different from the sape types of Sarawak and Kalimantan as documented by Matusky, and even the Bugis kecapi from Tawau, Sabah, studied by Daud (2011).

The age of Unsud's sundatang, suggests that distinctive boat lutes were being made and played hundreds of years ago in Tambunan which was then a remote interior area of Sabah. Brandeis recognises the Rungus sundatang as the forebear of similar box-shaped lutes in Palawan and Mindanao. On the other hand, the horse or deer head carvings on the gagayan and the cut-out nut section on its pegbox are somewhat similar to those on boat lutes documented in by Brandeis in the Philippines. It is possible that the local Lotud gagayan may have developed under influence from Philippine boat lutes 
through coastal trade generations ago. But this is speculative and this requires more research. It appears, nevertheless, that northern Borneo may have been a source for diverse kinds of long-necked boat lutes from different cultures in previous eras.

More research needs to be done specifically on long-necked lutes from other Dusunic groups, and any such instruments among other indigenous cultures in Sabah. It would also be providential if any surviving Iranun kudiapi from Sabah was found, so that structural linkages to the either the Sabah lutes, such as gagayan, or else to the Maranao kutiyapi of the Philippines could be determined. With the sudden cessation of gagayan performance in Tuaran and the gradual decline of the sundatang from Tambunan, these worthwhile performance traditions will become lost as new digital media takes the place of traditional entertainment.

\section{Acknowledgements}

I wish to acknowledge all the sundatang and gagayan performers who have allowed me to record their music over the years. I also want to thank Dr. Paul Porodong, Research Associate, Institute of Borneo Studies, Universiti Malaysia Sarawak (UNIMAS) for checking my spelling of Rungus terms and providing information about sundatang players from Kudat, Miss Judeth John Baptist, Operations Manager, Koisaan Cultural Village, Penampang, and also En. Frankie (son-in-law of Madam Kimoi) for checking my gagayan information and spelling of Lotud terms, and from Tambunan, En. Julius Kulip, Ethnobotanist, Institute of Tropical Biology and Conservation and Fellow of Borneo Institute for Indigenous Studies (BorIIS), Universiti Malaysia Sabah (UMS), for botanical information, my nephew Johan Adam Kitingan, and my husband Laurentius Kitingan for checking my information on the Kadazan Dusun sundatang. I also wish to thank Dr. Oliver Valentine Eboy, Senior Lecturer, Geography Programme, Faculty of Social Sciences and Humanities, and Research Fellow, BorIIS, UMS, for preparing the map, and especially Miss Fifiana Christin Morie for taking the time to convert my musical transcriptions into digital format.

\section{Glossary}

atob - "cover" (Rungus), the outer layer of wood that covers the of the inner back layer of a Rungus sundatang soundbox

batangkung - a duet by Lotud gagayan performers

binanjou - "deer" (Lotud), the deer-head carving at the end of a gagayan soundbox

biningkoko - decorative carving at the end of a Rungus sundatang pegbox

bobolizan - priestess of the traditional Rungus religion

bugang - a legendary eagle-like monster that attacked people in longhouses on the Tambunan plain

busul - "buttocks" (Rungus), the base of the soundbox of a Rungus sundatang

gagayan - the large long-necked lute played by Lotud men

gambus - a multi-stringed, pear-shaped lute of middle eastern origins, found in certain coastal communities of Sabah

giman - a plant with long roots traditionally used for the fretted string on a Kadazan Dusun sundatang, and also formerly used for gagayan strings

hontol - brass or wire strings on a Rungus sundatang

inan - "body" (Rungus; Lotud), the soundbox on a boat lute

kangkab - "chest", the front of a Rungus sundatang

kawot - brass or metal wire (Kadazan Dusun) used for the unfretted string on a sundatang

$k a z a b$ - "shoulders" (Rungus), the top of the soundbox of a Rungus sundatang, around its neck

$k e c a p i$ - the boat lute played among the Bugis community

$k u c a p i-$ a common term for boat lutes in the Philippines

$k u d a$ - "horse" (Lotud; Malay), the horse-head carving at the end of a Lotud gagayan

$k u d i a p i$ - the boat lute formerly played among the Iranun of Sabah; no longer extant

$k u k u$ - "tail" (Lotud), the carving of an animal's tail at the end of a gagayan pegbox

kulipapo - "softwood" (Lotud)

kutiyapi - the boat lute of the Maranao of Mindanao 
lapazan - the 'fixed fret' or piece of sopinit that fastens the melodic string on a Rungus sundatang to its neck

likud - "back" (Rungus), the inner back cover of a Rungus sundatang

$l o b u$ - tiny resonance holes on the front of a Lotud gagayan

magarang - Kadazan Dusun dance from Tambunan

magarang sundatang - rare sedate dance by a couple accompanied by the sundatang from Tambunan

mongigol - general term for Rungus dancing

nangko - common jackfruit tree (Artocarpus integer; Malay nangka)

obuk - the strings on a gagayan

odung - "nose" (Lotud), the string-holder on the front of a gagayan

pinonodu - "wedge" (Kadazan Dusun), the bridge on the front of a sundatang

pongigalan - music played by the Rungus gong ensemble

pongiruson - "the place that you tune" (Kadazan Dusun) for tuning pegs on a sundatang

pongisusan - "the place that you turn" (Kadazan Dusun) another term for tuning pegs on a sundatang

pongombitan - "the place that you pluck" (Kadazan Dusun) for the strings on a sundatang

randangan - "handle", the neck on a Rungus sundatang

rinait - sacred ritual poetry memorised and chanted by priestesses in traditional Dusunic religions

ruang - "space" (Lotud), the large resonance hole in the outer layer of the back cover of a gagayan soundbox

sape - the long rectangular boat lute of Sarawak and Kalimantan; also called sapeh, sampe, according to dialect and location

simbong - "earrings" (Lotud), the tuning pegs on a gagayan

soludon - the frets on a Lotud gagayan

sopihut - beeswax (Tambunan dialect, Kadazan Dusun) also called sopilut, sopinit in other dialects and languages

sopogandangan - gong ensemble from Tambunan consisting of a hand-held gong, and single-headed drum and seven hanging gongs of various types

sundatang - different kinds of double-stringed boat lutes played in various Dusunic cultures in Sabah tansi - nylon fishing line used nowadays for the fretted string on a sundatang from Tambunan (also called tangsi)

tikiu - "tail" (Kadazan Dusun), the support at the base of a sundatang from Tambunan

timadang - a forest jackfruit tree (Artocarpus odorartissimus; Malay tarap) among the Kadazan Dusun

timbok - a lady's bun (Kadazan Dusun) used for the pegbox on a sundatang from Tambunan

tinan - "body" (Kadazan Dusun), the soundbox of a sundatang

tinggayan - "the place that you hold" (Kadazan Dusun), the neck of a sundatang from Tambunan

tinondot - gong ensemble music from Tambunan

todung - "nose" (Kadazan Dusun, and also Rungus), the stringholder on the front of a sundatang

tohingo' - "ears" (Rungus), refers to the tuning pegs on a Rungus sundatang

tonok - "calf of a leg" (Lotud), referring to the neck of a gagayan

tontog - single-headed drum played in the Rungus gong ensemble

tuhu - "head" (Kadazan Dusun) also used for the pegbox on a sundatang from Tambunan

tukod - "gum/glue" (Lotud), referring to the beeswax that sticks the gagayan melodic string to its neck

turali - noseflute played in Dusunic cultures

tutub - "cover" (Lotud), two layers of thin wood that cover the back of a gagayan soundbox

$u l o b$ - frets on a Rungus sundatang, mounted in beeswax under the melodic string

ulu - "head" (Rungus), the pegbox on a sundatang

wiriwiri - decorative cloth or tassel hung from the end of a gagayan pegbox

\section{Endnotes}

${ }^{1}$ This article has been adapted and updated from my paper entitled "The Long-Necked Lutes Sundatang and Gagayan of Sabah and Their Performance: Disappearing Traditions" that was presented at the $12^{\text {th }}$ International Borneo Research Council Conference that was held at Universiti Malaysian Sabah from 5-7 July 2014. 
${ }^{2}$ Sabah has approximately 60 Austronesian languages of whom around 33 are indigenous to the state itself and mostly comprise the indigenous Dusunic, Paitanic and Murutic Families of Languages. Previously, I have sometimes used the ambiguous term isoglot to describe speakers of these indigenous languages. Since some scholars apply this to dialects, however, I no longer the term for distinct language groups.

${ }^{3} \mathrm{Kg}$. is an abbreviation of Kampung (village), the official designation of a village in Malaysia.

${ }^{4}$ I have deliberately avoided using the term "tail piece" and instead have used

"stringholder" for the 'nose' on the front of these lutes, so as to avoid confusion with the tikiu or "tail" at the base of the body of a sundatang from Tambunan and the kuku or "tail" carved at the end of the pegbox of a Lotud gagayan.

${ }^{5}$ When I originally recorded Kimoi playing sundatang in 1985, I was not yet familiar with the nuances of the Dusun language nor of the local usage of the Sabah Malay dialect. Hence, some of these terms have been corrected here from my earlier publications (Pugh-Kitingan, 1988, p. 42; 2003, 29). Recently, I asked her the name for the neck of the instrument, but she could not recall it.

${ }^{6}$ In ancient times, the Dusun of today's Tambunan District (that takes its name from the Tambunan dialect spoken in Kg. Karanaan and nearby villages) lived in longhouses. Kg. Karanaan itself had three longhouses. According to legend, at one time this village was attacked by a large, eagle-like, monster who regularly flew into a longhouse at night through the open space between the eaves and the wall, and killed or carried off sleeping children and small adults to eat. People say streaks of flames were emitted from its tail as it flew. One night, Unsud's ancestor who had made the sundatang hid near the wall where the creature flew in under the eaves, holding the instrument. As the creature entered, he clubbed it to death with the sundatang, thus saving the people from being killed. There are variations on this legend today throughout villages in Tambunan District.

${ }^{7}$ Unsud said that whenever he took out the instrument to show and play for visitors, it would suddenly rain heavily. Indeed, my recording of his performance was spoiled by heavy rain on the zinc roof of his bamboo house. Yet, I also observed him carrying the sundatang to local Kaamatan harvest festivals during fine weather

\section{References}

Alut, A.T. (1991). Pengunaan muzik tradisi Kadazan/Dusun Labuk dalam penyembahan ada Tuhan. [Unpublished bachelor's thesis]. Sabah Theological Seminary, Kota Kinabalu.

Bala, B. (2005). Thalassocracy. A history of the medieval Sultanate of Brunei Darussalam. School of Social Sciences, Universiti Malaysia Sabah.

Brandeis, H. (2012). Boat lutes in the Visayas and Luzon-traces of a lost tradition. Musika Jornal, 8, 2-103.

Brandeis, H. (2017). Kudyapi, a boat lute odyssey. Agong 20(6), 22-37.

Brandeis, H. (2019). Boat lutes of the Philippines. Ethnographia, 1(3), 6-72. https://doi.org/10.31250/2618-8600-2019-1(3)-6-72.

Daud, A. (2011). Muzik kecapi ensembel diaspora Bugis di Tawau, Sabah. [Unpublished bachelor's thesis] University of Malaya.

Ethnologue $^{\circledR}$. (2016). Ethnologue of the world's languages. www.ethnologue.com.

Gowing, P.G. (1979). Muslim Filipinos—heritage and horizon. New Day Publishers.

McKaughan, H.P. (1996). Preliminary comments on Iranun of Sabah, Malaysia and Maranao of Mindanao, Philippines. Paper presented at the Borneo Research Council Fourth Biennial International Conference, 10-15 June, Universiti Brunei Darussalam.

Matusky, P. (1986). Aspects of musical style among the Kajang, Kayan and Kenyah-Badang of the Upper Rejang River: A preliminary survey. Sarawak Museum Journal, 36 (57), 185-230.

Matusky, P., \& Tan S.B. (2017). The music of Malaysia. The classical, folk and syncretic traditions (Second edition). Routledge.

Porodong, P. (2018). Rungus. In K. Marriappan \& P. Porodong (Eds.), Murut \& pelbagai etnik kecil lain di Sabah (pp. 109-128). Institut Terjemahan Bahasa Malaysia \& Universiti Malaysia Sabah.

Pugh-Kitingan, J. (1988). Instruments and instrumental music of the Tambunan Kadazan/Dusun. Sabah Museum and Archives Journal, 1(2), 24-61.

Pugh-Kitingan, J. (2003). Alat-alat muzik dan muzik instrumental Kadazandusun Tambunan. Pejabat Kebudayaan dan Kesenian Negeri Sabah.

Pugh-Kitingan, J. (2007). From Brunei? Preliminary enquiries about Iranun gong-making and metalwork at Tempasuk, Sabah, Malaysia. In L. Billings \& N. Goudswaarde (Eds.), Piakandatu ami Dr. Howard P. McKaughan (pp. 225-229 with photographs on CD). Linguistic Society of the Philippines and SIL Philippines.

Pugh-Kitingan, J. (2017). Sources, sounds and meanings of turali (noseflute) music in Dusunic cultures of Sabah. Malaysian Music Journal, 6 (2),1-28. 
Regis, P. (1989). Demography. In J.G. Kitingan \& M.J. Ongkili (Eds.), Sabah 25 Years Later 1963-1988 (pp. 405-450). Institute for Development Studies, Sabah.

Smith, K.J. (2011). Introduction to the Iranun of Sabah. In J.U.H. Chin \& K.J. Smith (Eds.), The Iranun of Sabah (pp. 1-22). Pelanduk Publications.

Warren, J.F. (1981). The Sulu zone 1768 - 1898. The dynamics of external trade, slavery, and ethnicity in the transformation of a southeast Asian maritime state. Singapore University Press.

Warren, J.F. (2002). Iranun and Balangingi. Globalization, maritime raiding and the birth of ethnicity. New Day Publishers.

\section{Biography}

Jacqueline Pugh-Kitingan is professor of Ethnomusicology in the Faculty of Social Sciences and Humanities and Head of the Culture, Heritage and Arts Cluster of the Borneo Institute for Indigenous Studies, at Universiti Malaysia Sabah, where she previously held the Kadazandusun Chair (2003-2015). She graduated BA Honours (Class I) from Monash University (1976) and PhD from the University of Queensland (1982) with theses on the music of the Huli of Papua New Guinea. She first came to Sabah in 1977, having married a member of the Kadazan Dusun, Sabah's largest indigenous group, in 1976. She has conducted ethnomusicological research among many of Sabah's cultures. Winner of two PEREKA gold medals, her research interests include music and language, music, dance and ritual processes, organology, ethnographic mapping, the sociolinguistic review of Ethnologue ${ }^{\circledR}$ descriptions of languages in Sabah, the megalithic culture of Tambunan, and the Sabah Native Courts and customary law. She is a Fellow of the Borneo Research Council, a member of the ICTM Study Group on Performing Arts in Southeast Asia, sits on expert committees of Jabatan Warisan Negara Malaysia, and was Adjunct Research Fellow of Anthropology in the School of Political and Social Enquiry, Monash University (2009-2010). 